chương trình phòng chống các rối loạn do thiếu iốt, tuy nhiên chương trình này thiếu đi tính bền vững với những hạn chế về kinh phí.

Số trẻ được sàng lọc lần hai là 159 trẻ dương tính trong lần sàng lọc đầu tiên. Trong lần sàng lọc thứ hai, số trẻ được chẩn đoán suy giáp bẩm sinh là 125 người với tỷ lệ dương tính thật là 1:635 và số trẻ được chẩn đoán dương tính giả là 34 trẻ. Trong đó có $38,2 \%$ trẻ bị suy giáp vĩnh viễn và $61,8 \%$ trẻ bị suy giáp thoáng qua. Kết quả này có sự khác biệt với các nghiên cứu của Mahin Hashemipour và cộng sự trên 204 bệnh nhân suy giáp bẩm sinh nguyền phát với tỷ lệ suy giáp vĩnh viễn là $59,8 \%[7]$ và nghiên cứu của Gaudino và cộng sự ở Pháp với tỷ lệ suy giáp thoáng qua và vĩnh viến lần lượt là $38 \%$ và $62 \%$ trong số 79 bệnh nhân.[8] Tỷ lệ suy giáp thoáng qua cao hơn có thể do thiếu iốt, quá tải iốt, truyền qua nhau thai của tự kháng thể ngăn chặn thụ thể thyrotropin (TSH), tăng tự kháng thể tuyến giáp hoặc uống thuốc kháng giáp.

Nghiên cứu của chúng tôi cũng cho thây sự khác biệt về chỉ số TSH lấy lần đầu tiên, TSH tĩnh mạch và FT4 tĩnh mạch giữa hai loại suy giáp vĩnh viễn và suy giáp thoáng qua $(p<0,001)$, kết quả ngày cũng tương đồng với nghiên cứu của tác giả Habib. A và cộng sự (2021)[4]. Ngoài ra nghiên cứu cũng cho thây một số những hạn chế như, mới chỉ dừng lại ở một bệnh viện và cỡ mẫu nhỏ, tính đại diện cho số lượng trẻ sinh ra là còn hạn chế. Quy trình sàng lọc mới chỉ dừng lại ở hai bước, lấy máu gót chẩn và tĩnh mạch nên dễ dẫn đến sai số

\section{KẾT LUẬN}

Tỷ lệ suy giáp bẩm sinh trên đối tượng được sàng lọc trong nghiên cứu của chúng tôi là tương đối cao, bên cạnh đó tỷ lệ suy giáp vĩnh viễn cần được điều trị kịp thời để giảm thiểu gánh nặng bệnh tật cho bệnh nhi

\section{TÀl LIỆU THAM KHẢO}

1. A. Büyükgebiz (2013), "Newborn screening for congenital hypothyroidism", J Clin Res Pediatr Endocrinol, 5 Suppl 1(Suppl 1), tr. 8-12.

2. J. Kopel (2020), "A global perspective on newborn congenital hypothyroidism screening", Proc (Bayl Univ Med Cent), 33(1), tr. 137-139.

3. D. S. Saleh, S. Lawrence, M. T. Geraghty và các cộng sự. (2016), "Prediction of congenital hypothyroidism based on initial screening thyroidstimulating-hormone", BMC Pediatr, 16, tr. 24.

4. A. Habib, A. Shojazadeh, M. Molayemat và các cộng sự. (2021), "Prevalence and predictive factors of transient and permanent congenital hypothyroidism in Fars province, Iran", BMC Pediatr, 21(1), tr. 264.

5. Z. Razavi và L. Mohammadi (2016) "Permanent and Transient Congenital Hypothyroidism in Hamadan West Province of Iran", Int J Endocrinol Metab 14(4), tr. e38256.

6. L. Pitts, W. McCormick và G. J. Mick (2019), "Congenital Hypothyroidism: 8-Year Experience Using 2 Newborn Screens in Alabama", Horm Res Paediatr, 91(5), tr. 319-328.

7. M. Hashemipour, S. Hovsepian, R. Kelishadi và các cộng sự. (2009), "Permanent and transient congenital hypothyroidism in IsfahanIran", J Med Screen, 16(1), tr. 11-6.

8. R. Gaudino, C. Garel, P.' Czernichow và các cộng sứ. (2005), "Proportion of various types of thyroid disorders among newborns with congenital hypothyroidism and normally located gland: a regional cohort study", Clin Endocrinol (Oxf), 62(4), tr. 444-8.

\title{
ĐốI CHIẾU ĐĂC ĐIỂM LÂM SÀNG VỚI HÌNH ẢNH NộI SOI VIÊM TAI GIỮA CẤP Ở TRẺ EM TẠI BỆNH VIỆN E TRONG GIAI ĐOẠN NĂM 2019 - 2020
}

\section{TÓM TẮT}

\footnotetext{
*Trường Đại học Y Dược, ĐHQGHN

**Bênhh viển E Trung Ương

***Bêenh viện Tré Em Hải Phòng

Chịu trách nhiệm chính: Nguyễn Như Đua

Email: nhuduanguyen@gmail.com

Ngày nhận bài: 7.9.2021

Ngày phản biện khoa học: 27.10.2021

Ngày duyệt băi: 11.11.2021
}

\author{
Nguyễn Như Đua*, Đoàn Thị Hồng Hoa*, \\ Trương Thị Thu Hương**, Bùi Duy Vũ $\tilde{u}^{* * *}$
}

Đặt vấn đề: Viêm tai giữa cấp (VTGC) là tình trạng nhiễm trùng, ứ đọng dịch trong tai giữa. Bệnh thường khởi phát đột ngột trong thời gian ngắn, với các triệu chứng lâm sàng và hình ảnh nội soi liên quan với nhau. Mục tiêu: Đối chiếu đăc điểm lâm sàng với hình ảnh nội soi viêm tai giữa cấp ở trẻ em tai Bênh viện $\mathrm{E}$ trong giai đoạn 2019 - 2020. Đối tượng và Phương pháp nghiên cứu: Nghiên cứu mố tả cắt ngang gồm 40 bệnh nhân dưới 16 tuổi, được chẩn đoán VTGC, được điều trị tại khoa Tai Mũi Họng của Bệnh viện $E$ từ tháng 9/2019 đến 4/2020. Kết quả và 
bàn luận: Sốt nhẹ: 37,5\%, sốt vừa: $20 \%$, sốt cao: $22,5 \%$; Đau tai nhe chiếm $40 \%$, đau tai nhiều $25 \%$; Không chảy tai $77,5 \%$, chảy tai chiếm 22,5\%; Màng nhĩ sung huyết chiếm $35 \%$, màng nhĩ phồng ứ mủ 42,5\%, màng nhĩ thủng 22,5\%. Kết luận: Kết hợp giữa triệu chứng lâm sàng với hình ảnh nội soi giúp chẩn đoán xác định và chẩn đoán giai đoạn của viêm tai giữa cấp từ đó đưa ra hướng dẫn điều trị cụ thể và phù hợp.

Từ khóa: Viêm tai giữa cấp.

\section{SUMMARY}

COLLATE THE CLINICAL CHARACTERISTICS WITH ENDOSCOPIC IMAGES OF ACUTE OTITIS MEDIA IN CHILDREN AT E HOSPITAL FROM 2019 - 2020

Background: Acute otitis media (AOM) is an infection and accumulation of fluid in the middle ear. The disease that usually begins suddenly and is in the short duration, with clinical symptoms relating to endoscopic images. Objective: Description of clinical characteristics of acute otitis media in children at Hospital E from 2019-2020. Materials and methods: A cross-sectional descriptive study, included 40 patients, under 16 years old, diagnosed with AOM, treated at the Department of Otolaryngology in $\mathrm{E}$ Hospital from 2019 September to 2020 April. Results and discussions: Mild fever: $37.5 \%$, moderate fever: 20\%, high fever: $22.5 \%$; Mild otalgia accounted for $40 \%$, severe otalgia $25 \%$; No ear discharge $77.5 \%$, ear discharge accounted for 22.5\%; congested tympanic membrane accounted $35 \%$, pus-filled bulging tympanic membrane $42,5 \%$, perforated tympanic membrane 22,5\%. Conclusions: Combine the clinical sumptoms and endoscopic images to be able to diagnose exactly and diagnose the stage of acute otitis media, thereby bringing out to make treatment guidelines specific and appropriate.

Key words: Acute otitis media.

\section{I. ĐẶT VẤN ĐỀ}

Viêm tai giữa cấp tính thường xẩy ra ở trẻ nhỏ lứa tuổi nhà trẻ, độ tuổi hay gặp nhất từ 24 tháng đến 6 tuổi. Có khoảng $80 \%$ trẻ em bị mắc viêm tai giữa trong quá trình phát triển, có $80 \%$

\section{KẾT QUẢ NGHIÊN CứU}

3.1. Đặc điểm lâm sàng triệu chứng đau tai với hình ảnh nội soi tai:

Bảng 1: Đối chiêu đặc điểm đau taî với hình ảnh nội soi màng nhĩ:

\begin{tabular}{|c|c|c|c|c|c|c|c|c|}
\hline \multirow{2}{*}{ Hà̀nh ảnh nội soi điểm lâm sàng } & \multicolumn{2}{|c|}{$\begin{array}{c}\text { Màng nhĩ } \\
\text { sung huyết }\end{array}$} & \multicolumn{2}{c|}{$\begin{array}{c}\text { Màng nhĩ } \\
\text { phồng ứ mủ }\end{array}$} & \multicolumn{2}{c|}{$\begin{array}{c}\text { Màng nhĩ } \\
\text { thủng }\end{array}$} & \multicolumn{2}{|c|}{ Tổng } \\
\cline { 2 - 9 } & $\mathbf{n}$ & $\mathbf{\%}$ & $\mathbf{n}$ & $\mathbf{\%}$ & $\mathbf{n}$ & $\mathbf{\%}$ & $\mathbf{n}$ & $\mathbf{\%}$ \\
\hline Không đau & 8 & 0,2 & 2 & 0,05 & 4 & 0,1 & 14 & 0,35 \\
\hline Đau tai nhẹ & 4 & 0,1 & 7 & 0,175 & 5 & 0,125 & 16 & 0,4 \\
\hline Dau tai nặn & 2 & 0,05 & 8 & 0,2 & 0 & 0 & 10 & 0,25 \\
\hline Tống số & $\mathbf{1 4}$ & $\mathbf{0 , 3 5}$ & $\mathbf{1 7}$ & $\mathbf{0 , 4 2 5}$ & $\mathbf{9}$ & $\mathbf{0 , 2 2 5}$ & $\mathbf{4 0}$ & $\mathbf{1 , 0}$ \\
\hline
\end{tabular}

Nhận xét: Bệnh nhi có triệu chứng đau tai mức độ nhẹ và nặng gặp nhiều ở nhóm có hình ảnh có nội soi màng nhĩ căng phồng ứ mủ, mức độ nặng chiếm tỷ lệ cao nhất 20\%.

3.2. Đặc điểm lâm sàng triệu chứng sốt với hình ảnh nội soi tai: trong tai giữa trước tuổi đi học từ [1].

Do đặc điểm cấu tạo giải phẫu vòi nhĩ trẻ em ngắn, rộng và nằm ngang hơn so với người trưởng thành. Trẻ em cũng dễ bị mắc các bệnh lý viêm nhiễm đường hô hấp trên đây là yếu tố thuận lợi giúp cho vi khuẩn lan lên tai giữa [2].

Dựa vào các triêu chứng lâm sàng và hình ảnh nội soi giúp phát hiện sớm, điều trị kịp thời để tránh các biến chứng có thể xẩy ra. Nếu không được điều trị đúng cách và kịp thời, bệnh có thể dẫn đến các biến chứng nguy hiểm như viêm tai giữa chảy mủ mạn tính, viêm xương chũm, liệt mặt ngoại biên, nghe kém hoặc mất thính lực, biến chứng nội sọ [3].

\section{II. ĐỐI TƯỢNG VÀ PHƯƠNG PHÁP NGHIÊN CỨU}

2.1. Đối tượng nghiên cứu: Đối tượng nghiên cứu gồm 40 bệnh nhân, tuổi nghiên cứu dưới 16 tuối, được chẩn đoán là VTGC, được tháng 9/2019 đến tháng 4/2020.

2.2. Phương pháp nghiên cứu. Phương pháp nghiên cứu mô tả cắt ngang có phân tích. Bệnh nhi được khảo sát bằng bộ câu hỏi được chuẩn bị chi tiết. Khám lâm sàng và Nội soi tai mũi hong.

2.3. Nội dung nghiên cứu. Đánh giá các triệu chứng lâm sàng mức độ từ nhẹ đến nặng; Các biểu hiện lâm sàng tại chỗ như đau tai, chảy tai; triệu chứng sốt, hình ảnh nội soi màng nhî qua các giai đoạn.

2.4. Các biến số nghiên cứu. Triệu chứng đau tai: không đau, đau tai nhe, đau tai năng;

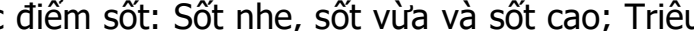
chứng chảy mủ tai: Có chảy mủ tai, không chảy mủ tai; Đặc điểm hình ảnh nội soi: Màng nhĩ huyết, căng phồng, màng nhĩ thủng.

2.5. Phân tích số liệu. Sử dụng phần mềm SPSS 20.0 và các thuật toán thống kê y học. đến $90 \%$ trẻ em bị viêm tai giữa có đọng dịch điều trị tại khoa Tai Mũi Họng của Bệnh viện $\mathrm{E}$ từ 
Bảng 2: Đôî chiếu đặc điểm triệu chứng sôt với hình ảnh nội soi màng nhĩ:

\begin{tabular}{|c|c|c|c|c|c|c|c|c|}
\hline \multirow{2}{*}{ Hình ảnh nội soi } & $\begin{array}{c}\text { Màng nhî̃ } \\
\text { sung huyết }\end{array}$ & \multicolumn{2}{c|}{$\begin{array}{c}\text { Màng nhĩ } \\
\text { phồng ứ mủ }\end{array}$} & \multicolumn{2}{c|}{$\begin{array}{c}\text { Màng nhĩ } \\
\text { thủng }\end{array}$} & \multicolumn{2}{|c|}{ Tổng } \\
\cline { 2 - 9 } & $\mathbf{n}$ & $\mathbf{\%}$ & $\mathbf{n}$ & $\mathbf{\%}$ & $\mathbf{n}$ & $\mathbf{\%}$ & $\mathbf{n}$ & $\mathbf{\%}$ \\
\hline Không sốt & 4 & 0,1 & 1 & 0,025 & 3 & 0,075 & 8 & 0,2 \\
\hline Sốt nhẹ & 7 & 0,175 & 2 & 0,05 & 6 & 0,15 & 15 & 0,375 \\
\hline Sốy vừa & 3 & 0,075 & 5 & 0,125 & 0 & 0,00 & 8 & 0,2 \\
\hline Sốt cao & 0 & 0,00 & 9 & 0,225 & 0,00 & 0,00 & 9 & 0,225 \\
\hline Tống sốn & $\mathbf{1 4}$ & $\mathbf{0 , 3 5}$ & $\mathbf{1 7}$ & $\mathbf{0 , 4 2 5}$ & $\mathbf{9}$ & $\mathbf{0 , 2 2 5}$ & $\mathbf{4 0}$ & $\mathbf{1 , 0}$ \\
\hline
\end{tabular}

Nhận xét: Tỷ lệ sốt gặp nhiêu ở nhóm bệnh nhi viêm tai giữa có màng nhĩ sung huyết hoặc căng phồng ứ mủ. Trong đó nhóm sốt cao gặp nhiều nhất ở bệnh nhi có màng nhĩ căng phồng ứ mủ với tỷ lệ 22,5\%.

3.3. Đặc điểm lâm sàng triệu chứng chảy tai với hình ảnh nội soi tai:

Bảng 3: Đối chiếu đặc điểm triệu chứng chảy tai với hình ảnh nội soi màng nhĩ:

\begin{tabular}{|c|c|c|c|c|c|c|c|c|}
\hline \multirow{3}{*}{$\begin{array}{l}\text { Triểu chứng } \\
\text { chảy mủ tai }\end{array}$} & \multicolumn{6}{|c|}{ Hình ảnh nội màng nhĩ } & \multirow{2}{*}{\multicolumn{2}{|c|}{ Tổng }} \\
\hline & \multicolumn{2}{|c|}{$\begin{array}{l}\text { Màng nhĩ } \\
\text { sung huyêtt }\end{array}$} & \multicolumn{2}{|c|}{$\begin{array}{l}\text { Màng nhĩ } \\
\text { phông ứ mủ }\end{array}$} & \multicolumn{2}{|c|}{ Màng nhĩ thủng } & & \\
\hline & $\mathbf{n}$ & $\%$ & $\mathbf{n}$ & $\%$ & $\mathbf{n}$ & $\%$ & $\mathbf{n}$ & $\%$ \\
\hline Không chảy mủ & 14 & 0,35 & 17 & 0,425 & 0 & 0,00 & 31 & 0,775 \\
\hline Có chảy mú & 0 & 0,00 & 0 & 0,00 & 9 & 0,225 & 9 & 0,225 \\
\hline Tống số & 14 & 0,35 & 17 & 0,425 & 9 & 0,225 & 40 & $100 \%$ \\
\hline
\end{tabular}

Nhận xét: Triệu chứng không chảy mủ tai ở bệnh nhi bị viêm tai giữa cấp chiếm tỷ lệ cao nhất $77,5 \%$. Triệu chứng chảy mủ tai có màng nhĩ thủng chiếm tỷ lệ 22,5\%.

\section{BÀN LUẬN}

4.1. Đối chiếu đặc điểm đau tai với hình ảnh nội soi màng nhĩ: Triệu chứng đau tai trên bệnh nhi bị viêm tai giữa cấp qua hình ảnh nội soi màng nhĩ thấy có đă̆c điểm với hình ảnh màng nhĩ sung huyết chiếm $35 \%$, phần lớn không có dấu hiệu đau tai hoặc chỉ đau tai nhẹ chiếm 30\%, triệu chứng đau tai nặng chỉ chiếm tỷ lệ rất thấp $5 \%$. Tỷ lệ bệnh nhi nhập viện điều trị có màng nhĩ phồng ứ mủ chiếm tỷ lệ cao nhất $42,5 \%$, nhóm bệnh nhi này ngoài các triệu chứng khác thì triệu chứng đau tai mức độ nhẹ và nặng chiếm tỷ lệ $37,5 \%$ còn lại là $5 \%$ không có triệu chứng đau tai dù màng nhĩ có dấu hiệu căng phòng kèm ứ mủ. Ở nhóm viêm tai giữa nội soi có màng nhĩ thủng chiếm tỷ lệ $22,5 \%$, trong nhóm này không có trường hợp nào bệnh nhi nhập viện với triệu chứng đau nặng, chỉ có đau nhẹ là $12,5 \%$ còn lại là không đau, do màng nhĩ thủng làm giảm áp suất trong tai giữa nên bệnh nhi không còn triệu chứng đau tai, bệnh nhi thường vào viện điểu trị với lý do khác.

Đau tai là triệu chứng cơ năng chủ quan của người bệnh, ở những trẻ lớn hoặc người lớn thì triệu chứng đau tai dễ dàng được khai thác hơn, nhưng với trẻ nhỏ thì triệu chứng này không điển hình và khó khai thác, đôi khi bố me cũng không nắm bắt được khi trẻ có biểu hiện đau tai, ở trẻ nhỏ đôi khi chỉ biểu hiện bằng lắc đâu quây khóc, lấy tay bứt vàng tai bên đau, đôi khi sờ lên tai là trẻ khóc, hoặc không nằm nghiêng được về bên tai đau cũng theo phân tích của Robert và James [2]. Cũng theo Shaikh và Rothman đau tai gặp ở các trường hợp bệnh nhi bị viêm tai giữa cấp tuy nhiên chỉ khoảng $50-60 \%$ phàn nàn bị đau tai còn lại thì biểu hiện qua các triệu chứng gián tiếp tại chố hoặc toàn thân [4],[5].

4.2. Đối chiếu đặc điểm triệu chứng sốt với hình ảnh nội soi màng nhĩ: Đối với nhóm màng nhĩ sung huyết chiếm 35\% thì không gặp trường hợp nào sốt cao, chỉ gặp trường hợp sốt nhẹ và sốt vừa chiếm tới $25 \%$, còn $10 \%$ bệnh nhi bị viêm tai giữa cấp nhưng không có triệu chứng sốt. Trường hợp nội soi màng nhĩ phồng ứ mủ chiếm tỷ lệ $42,5 \%$, thì có các triệu chứng sốt, với sốt cao chiếm tỷ lệ $22,5 \%$, sốt vừa chiếm $12,5 \%$ và sốt nhe chiếm $5 \%$ còn lại là không sốt có một trường hợp chiếm 2,5\%. Như vậy dấu hiệu sốt, nhất là sốt cao có xu hướng tăng nhiều ở nhóm có màng nhĩ căng phồng ứ mủ, nguyên nhân có thể do tình trạng ứ mủ đọng ở trong tai giữa gây nên tình trạng viêm và nhiểm trùng làm cho bệnh nhi có triệu chứng sốt và thường sốt cao. Theo nghiên cứu của Niemela và Staphen triệu chứng sốt gặp trong viêm tai giữa cấp là 45,5\% [6],[7].

4.3. Đối chiếu đặc điểm triệu chứng chảy tai với hình ảnh nội soi màng nhî: Trong nhóm đối tượng được điều trị viêm tai giữa cấp tính tại bệnh viện thì bệnh nhi có triệu chứng chảy tai chiếm $22,5 \%$, ở nhóm này hình ảnh nội soi màng nhĩ thây màng nhĩ có lỗ thủng, 
thường do nguyên nhân tình trạng ứ đọng mủ trong hòm nhĩ căng làm tăng áp lực và làm thủng màng nhĩ thoát mủ ra ngoài. Bệnh nhi không có triệu chứng chảy mủ tai chiếm tỷ lệ $77,5 \%$, nhóm này hình ảnh nội soi màng nhĩ thấy sung huyết hoặc căng phồng ứ mủ. Những bệnh nhi khi nhập viện điêu trị với lỗ thủng màng nhĩ và có chảy mủ tai thường là những trường hợp đến viện muộn, trong tình trạng tự điều trị hoặc theo dõi ở nhà không đúng cách nên khi có dấu hiệu chảy mủ do có lỗ thủng màng nhĩ mới được đưa đi khám điều trị.

So sánh với nghiên cứu của Kay và cộng sự cùng Ah-Tye và cộng sự trên những bệnh nhi được đặt ống thông khí trong giai đoạn viêm tai giữa cấp có từ $26 \%$ đến $75 \%$ có dấu hiệu chảy mủ tai [8],[9]. Ở những bệnh nhi khi được nạo VA thì cũng làm giảm $10 \%$ phải đặt ống thông khí lại so với đặt ống thông khí đơn thuần. Do đó lựa chọn phương pháp điều trị phù hợp đúng giai đoạn tránh tình trạng chảy mủ tai, đau, sốt làm giảm chất lượng cuộc sống của bệnh nhi.

\section{KẾT LUÂN}

Đánh giá mối liên quan giữa triệu chứng lâm sàng với hình ảnh nội soi màng nhĩ trong viêm tai giữa cấp giúp xác định chính xác giai đoạn của bệnh viêm giữa cấp và đưa ra phác đồ điều trị phù hợp, kịp thời tránh bỏ sót bệnh và các biến chứng do viêm tai giữa cấp có thể gây ra.

\section{TÀI LIÊU THAM KHẢO}

1. Amina Danishyar, John V. Ashurst: Acute Otitis Media. StatPearls Publishing LLC. (2021)

2. Robert M Siegel, James P Bien: Acute otitis media in children: A continuing story. Pediatrics in Review; Vol.25 No.6; 25(6):187-93 (2004).

3. Helen Atkinson, Sebastian Wallis et al: Acute otitis media. Postgraduate Medicine; 127(4): 386390 (2015).

4. Shaikh, N. et al. Responsiveness and construct validity of a symptom scale for acute otitis media. Pediatr. Infect. Dis. J. 28, 9-12 (2009).

5. Rothman, R., Owens, T. \& Simel, D. L. Does this child have acute otitis media? JAMA 289, 1633-1640 (2003).

6. Niemela $M$, Uhari $M$ et al: Lack of specific symptomatology in children with acute otitis media. The padiatric infectious disease journal; 13(9):765-768 (1994).

7. Staphen Berman: Management of acute and chronic otitis media in pediatric practice. Current opinion in pediatrics; 7(5):513-22 (1995).

8. Kay, D. J., Nelson, M. \& Rosenfeld, R. M. Meta-analysis of tympanostomy tube sequelae. Otolaryngol. Head Neck Surg. 124, 374-380 (2001).

9. Ah-Tye, C., Paradise, J. L. \& Colborn, D. K. Otorrhea in young children after tympanostomytube placement for persistent middle-ear effusion: prevalence, incidence, and duration. Pediatrics $107,1251-1258$ (2001).

\title{
ĐÁNH GIÁ CHỨC NĂNG ĐAI TIÊN VÀ MỘT SỐ YẾU TỐ LIÊN QUAN SAU PHẪU THUẦT Nộ̂I SOI CẮT TRƯớC THẤP ĐIỀU TRI UNG THƯ TRỰC TRÀNG
}

\author{
Hồ Hữu An*, Triệu Triều Dương*, Diêm Đăng Bình*, \\ Nguyễn Văn Trưởng*, Lê Văn Quốc*, Vũ Ngọc Sơn*, \\ Phạm Thị Huế*, Ngô Thị To*, Trần Thị Hà*, \\ Lê Đăng Trung*, Nguyễn Thị Tri*
}

\section{TÓM TẮT}

Đă̆t vấn đề: Rối loạn chức năng đại tiện sau phẫu thuật là vấn đề thách thức ảnh hưởng nhiều đến chất lượng sống của bệnh nhân sau phẫu thuật. Mục đích nghiên cứu nhắm đánh giá chức năng đại tiện của bệnh nhân sau phẫu thuật nội soi cắt trực tràng trước thấp. Phương pháp nghiên cứu: Nghiên cứu mô tả tiến cứu trên 82 bệnh nhân ung thư trực tràng được

*Bệnh viên Trung ương Quân đội 108

Chịu trách nhiệm chính: Hồ Hữu An

Email: bs.hohuuan83@gmail.com

Ngày nhận bài: 14.9.2021

Ngày phản biên khoa hoc: 29.10.2021

Ngày duyệt bài: 17.11 .2021 phẫu thuât nôi soi cắt trước thấp từ tháng 7/2018 đến 7/2020. Đánh giá theo thang điểm Hồi chứng cắt trước thấp (LARS) và Wexner tai thời điểm 3 tháng, 6 tháng và 12 tháng. Kết quả: tuổi trung bình 62,3 tuổi, có $65,9 \%$ nam và $34,1 \%$ nữ. Chức năng đại tiên thay đổi rõ rệt sau 1 năm: điểm trung bình LARS sau 3 tháng, 6 tháng và 12 tháng lần lướt là 17,$6 ; 14,0$ và 10,6 . Trong đó $56,1 \%$ bệnh nhân không có LARS sau 3 tháng tăng lên $75,6 \%$ sau 12 tháng. Tỷ lê bệnh nhân LARS nặng sau 3 tháng $26,8 \%$ giảm còn $14,6 \%$ sau 12 tháng. Điểm Wexner: sau 3 tháng là 5,9 giảm còn 3,4 sau 12 tháng. Tỷ lệ bệnh nhân đại tiện bình thường sau 3 tháng $28,0 \%$ tắng lên $46,3 \%$ sau 12 tháng. Sau 3 tháng có $11,0 \%$ bệnh nhân mất tự chủ hoàn toàn giảm cờn $7,3 \%$ sau 12 tháng. Các yểu tố: hóa xạ trị tiền phẫu $(p=0,017)$, vị trí khối u $(p=0,02)$ 